Journal of Social Sciences 5(4): 342-347, 2009

ISSN 1549-3652

(C) 2009 Science Publications

\title{
The Organization of Cultural Tourism by the Community People in the Region of Toong Kula Rong Hai
}

\author{
${ }^{1}$ Amkha Saeng-Ngam, ${ }^{1}$ Songkoon Chantachon and ${ }^{2}$ Prasopsuk Ritthidet \\ ${ }^{1}$ Department of Thai Studies, Faculty of Art and Culture, \\ The Research Institute of Northeastern, Mahasarakham University, Thailand, 44150 \\ ${ }^{2}$ Department of Curriculum and Instruction, \\ Education Faculty, Rajabhat Mahasarakham University, Thailand, 44000
}

\begin{abstract}
Problem statement: The real concern of this study was relevant to the issue of how to encourage Toong Kula Rong Hai to become one of the tourists' attractions distinctively focusing on organic agriculture and cultural tourism. Approach: This was a Qualitative case study conducted in the Koo-Kaa-Sing village, Koo-Kaa-Sing sub-district, Ka-Sate-Wisai district, Roi Et province, geographically recognized as part of Toong Kula Rong Hai in the Northeastern part of Thailand. The subject of this study was obtained by means of Specified Random Sampling. The sample used consisted of folk philosophers, specialists, Buddhist monks, the village headman, the sub-district headman, the Assembly of Cultural Affairs/the Cultural Council, experts, highly qualified persons, teachers, housewives, youths and tourists; they accounted for the total of 15 subjects/respondents. The data were gathered by means of surveys, observations, interviews, small group meeting and workshop. The results obtained were presented in descriptive analysis. Results: The findings revealed that the Community of Koo-Kaa-Sing sub-district had set up a club to be intent on and responsible for tourism promotion. They, however, enjoyed the firm support of the village headman, the sub-district headman and the municipality officials. They utilized the unique available resources as the points of sale. The target tour groups were Tourists interested in Cultural Tourism and students on study tour. However, this Tourism enterprise in the long run tend to be sustainable as long as people enjoy their work and feel happy with their roles to partially play in dealing with the conservation of local cultures and customs. Conclusion: The highly plausible ways of practice by means of allowing the community staff to organize the cultural tourism by developing the existing club in terms of efficient administration to such an enormous extent of strength. It is necessary to establish the tourism network in Toong Kula Rong Hai by creating all the six learning bases to be equipped with permanent instruction media and exhibition/ boards and at the same time adjusting the paradigm of the local government organization and providing the community people with knowledge and understanding of tourism run by the community. So that the community people are urged earnestly to cooperate and take mutual parts and play their wholehearted or voluntary roles.
\end{abstract}

Key words: Tourism management, management of cultural tourism, tourism management manipulated by the community, Toong Kula Rong Hai community

\section{INTRODUCTION}

The location of Koo-Kaa-Sing village, Koo-KaaSing sub-district, Ka-Sate-Wisai district, Roi Et province is in Toong Kula Rong Hai region, in the Northeast of Thailand. This area of Thailand is generally known as the most arid highland where the native people have to withstand and suffer all year round from the worst drought. But the historical evidence suggests that it was once a cultural source of civilization as was evident from the discovery of antiquated baked clay pottery utensils portraying late prehistoric times. Luckily, a lot of worthwhile evidence has been discovered and preserved, including some historical sites such as Cambodian or Khmer styled antiques, very old streets and ponds have been perfectly preserved in the peripheral area of the community and we all as the present generation can merely pay a visit

Corresponding Author: Amkha Saeng-Ngam, Faculty of the Art and Culture, The Research Institute of Northeastern, Mahasarakham University, Thailand, 44150 Tel: +66-43-741686 Fax: +66-43-741686 
and let go your great imagination. Now, let's imagine Housewives being busy processing their distinctive indigenous silk. However, one day, exactly when cannot be told the government has unbelievably reached this outpost-of-civilization area "Toong Kula Rong Hai".

They approached with a strategic plan focusing primarily on the improvement of jasmine rice plantation and cultivation, the local people with hard luck stories had been informed of the urgent action to be taken to produce the jasmine rice of the highest quality and in the largest approximate amount. The point is that they need to gear up the jasmine rice to become the worldwide well-known for its quality and its qualified yields when compared to other competitors' yields. This implies that the Toong Kula Rong Hai will be officially endorsed as a community having innate capacity and abundance of social capital quite appropriate to be directly promoted as a tourist attraction the approval of an injection of capital to enhance the possibility of accomplishment.

After the government support has been given to this community to be a tourist attraction. More supportive action has been consequently taken activities for the highly persuasive propaganda purpose under the name, "Eat rice in paddy field and enjoy the scene of folk people in silk dresses" (this denotes time for lunch) and also another occasion "Eat rice "Paa-Laeng" (which denotes a more formal feast at dinner time) and during the feast the guests may be entertained by exquisite Art and Cultural performances. The tasks having been organized to partially signify the auspicious time, a joyous celebration when an important task has been accomplished within the timeframe and in accordance with the government policy. The arrogant feast has neither organized in order to promote nor give rise to the community strength. Apparently, the external dancers or performers invited were all selected and supervised by the instructors or trainers from the College of Dramatic Arts, Whereas, the Vocational College would deal with food and drinks. Then, all of them got paid. That is to say, no role was shared nor played by any community folks; neither profits nor extra income were gained by them. It was a pity that such opportunities would be the high time the customs, rituals and local cultures could possibly be renovated and conserved. For goodness' sake, it should be high time when they should be more than a little proud of themselves rather than just a propaganda about tourism.

The past development process merely took aim at ensuring conformity with 'consumerism trend'. The community was, in turn, taken over by powerful outsiders/the outside world to such a high degree that they eventually lost self-assurance. Then, as a result, the former rich/fertile resources were deteriorated so badly that so many social problems emerged as well as the consequent impact on the detriment of decent principles/precepts, traditions, cultures and customs, which have been their normal ways of living ${ }^{[1]}$. Based on the ministers' proposal, as mentioned above the Government had taken up as a recommendation that the Toong Kula Rong Hai should be further developed to become a tourism attraction on account of the fact that it is located in the middle or the hub of the Indo-China Peninsula which makes it easier and more convenient to communicate or get in touch with other neighboring countries Because of that geographical advantage, it is high time Thailand can boom and enlarge the international trades as well as industrialized commodity goods. On the contrary, such consumerism could result in an imminent contingent disaster on the local people themselves and likely to have a substantial impact on the community people and a worse condition, the impact on the community environment. So, the deep knowledge to be acquired about the past would contribute to finding a comprehensive solution to the large-scale crisis, which, in turn, could ultimately enhance the sustainable conservation tourism and as a result, can also maintain not only the cultural aspects, but also their simple ways of living. On the other hand, the existed works of arts and the local arts and crafts and various forms of dramatic, decorative, architectural performing and visual arts as well can be utilized to cope with the current advent of economic crises ${ }^{[2]}$. In short, pursuing the past in order to pick up the feedback or reviving its same old value to find out the actual cause and critically diagnose which solution works best in the present circumstance. This is not to persuade someone to dwell on one's past, but to reflect on it. In case, some good ideas emerge, think over them and consider if they are applicable to the present day's circumstances; or else, to see if the past occurrences can lead to the reformation of brand new ways/patterns of living. With respect to the community development, it is essential for the success in the rural development that the folk cultural reminiscence must be of the most urgent priority. The first two focal aspects of community development account for the economic and cultural factors ${ }^{[3]}$. For these particular reasons, the Tourism to be organized by community is, thus, one of the options that allows the local people to manage on their own and they could succeed in managing by bringing various resources available in the community to be the preliminary capital of tourism management and the next stage of is the development of community people who are the pool of manpower for the new 
venture. This enterprise will be firmly based on its sustainability and its ability to bring real benefits for the locality $^{[4]}$. Still, they desperately hope that the community will be able to keep up with the community's culture and being able to properly subsist on the present Social conditions.

\section{MATERIALS AND METHODS}

The research site was Koo-Kaa-Sing Neighborhood, Koo-Kaa-Sing sub-district, Ka-SateWisai district, Roi Et province. This research was a qualitative study the sample was obtained by Specified Random Sampling from persons in the-know-including experts, the municipality/specialists, mayor of KooKaa-Sing sub-district, the village headmen, the managing directors of the community tourism including the president of the tourism-promoting club, the subdistrict Cultural Council, groups of housewives, teachers, youths and tourists account for the total of 20 respondents. The research data are gathered by means of surveys, interviews, the observations both participated and un-participated, small-group meetings and workshops and the research results are presented by means of descriptive analysis.

\section{RESULTS}

The research findings were found as follow:

- New local organizations have just been set up, that is, the tourism-promoting club of the Koo-KaaSing sub-district, the newly-established folk cultural and custom network groups included food group, home stay group, folk music group, folk literature group, youth performance group and the enthusiastic audience group interested in cultural activities and community shows

- The results of organizing panel discussions to find out the tourism identity of the community indicated that this community would rather become the cultural tourism agency, when considering the six bases of folk wisdom learning. They revealed: (1) cambodian ancient remains; (2) locally made silk; (3) the botanic garden demonstrating newly introduced theories; (4) folk wisdom heritage museum; (5) folk literature and (6) folk perforated paper-cutting patterns and, However, the selling point of learning bases are dependent upon the learners being able to directly expose to the activities and have a chance to get a closer look and learn by doing from direct folk wisdom and work shop, such as trying out weaving cloth and cutting paper by taking after the perforated design

- Having got the ideas and realization of the community cultures and also the principal idea of the community's tourism management which says "The amount of money having earned cannot be always regarded as a sole indicator of success in managing the tours"; "The money gained solely a factor that drives the working process toward the aim". The real goal of tourism management by community is to conserve ancient sites, significantly, it is managed to maintain customs and cultures. Particularly, when the community people have learned altogether the system of work and they have altogether renovated festivals and customs, as well as feeling proud. Best of all, their relationships have become amicable, friendly and in harmony. Their happiness means everyone is happy. Having happiness in common is regarded as a great success

- There exists the conversation trend particularly in the existed groups including the museums, the botanic gardens demonstrating newly introduced theories, the local silk cloth, the perforated paper cutting pattern group, the tourist guides and since the dynamic workforce has resulted in working spirit and, at the same time, their conscious minds and the awareness of conservation are raised

- All those involved have every reason to be proud of and happy with their possessing and maintaining their community's cultural identity which they could at times proudly present to or mutually exchange with tourists. In turn, their flagging spirits have resulted in such a strong impulse to conserve their cultures that have hardly ever felt before. Furthermore, they have been motivated by a deep desire for the proud feeling to be perceived and shared in common by all the community people

- Tourism can provide the community people with considerable income being distributed among the tourism-promoting club, the home stay cluster, the cook staff, the ritual organizers, the tourist guide teams, fine silk base and botanic garden demonstrating newly introduced theories base

- People in the community have great opportunities to learn the pathway of development right from their own community cultures. They have learned the community problems and in unity, by means of brain storming to solve their own problems. This way of struggle, more or less, is the best way to escape from the domination of the people from the outside of the community 
The set of guidelines for the community to follow in tourism management:

- To develop the club management to such an appropriate degree of strength. One of the right methods is to advertise or publicist in the "Classified Advertisements" about job vacancy; those interested or those with relevant advantages or disadvantages to the position wanted are cordially persuaded to apply for the challenging duties of tourism management, or else, for the wealthy person who consider himself/herself capable of running such an enterprise solely for social benefits will be wholeheartedly welcome and enlisted either as a partnership in this joint venture or as a new member of our cooperative enterprise. Such a decision will enable all of the members to become wholly responsible and consciously aware of their involvement and liability and accordingly, dedicate their entire efforts to the tourism club

- To adjust the government officials leading authorities' and politicians' paradigms as well as to enable the community members to understand the worthwhile ideas of tourism undertaken by the community by offering them the training courses and organizing panel discussions where they can mutually exchange their knowledge which as a result can encourage the tourism managed by community to such a significant extent that the successful outcome can be met

- To renovate the custom of sprinkling water onto the pagodas, the traditional practice initiated by folk wisdom and those who believed would result in a spiritually intricate interrelation/involvement between human being and historical/archeological sites. Such belief resulted in the conservation of the ancient remains. Owing to The mythical folklore the God ghost/spirit insisted on dwelling in the ancient site. The folks called him "God ghost/spirit Hong Daeng See Ha Rat" With respect to this belief. There existed, on the one hand, a common sense of paying respect/homage to the historical sites. The worshippers, on the other hand, became amicable.

- To develop the culture learning base both which were a public place base and a private house base to a desirable standard by equipping it with a variety of media such as knowledge exhibition bulletin boards/plates, directing the steps of doing activities, displaying the port folio of folk philosophers' works, delineating tracks, organizing tourist attraction proportionately and hygienically

- To develop knowledge source in the community to enable tourists to make seasonal tours, by studying and making surveys so as to develop supplementary living knowledge sources, made itinerary for tourists that makes them possible to plan their travel all year round

- To develop career groups enable the career groups to produce folk wisdom goods as the community products in a variety of forms and styles for low price sales to meet the tourists' requirements

- The Fine Art Department, Ministry of Cultural Affairs is supposed to speed up in order to catch up with the transfer of authoritative power of managing historical resources and archaeology to the community authority order to develop tourism on a basis for sustainability

\section{DISCUSSION}

With regard to Cultural tourism management by Koo-Kaa-Sing community, Koo-Kaa-Sing sub-district, Ka-Sate-Wisai district, Roi Et province, the findings revealed that the Koo-Kaa-Sing villagers organized a group of enthusiastically inspired native innovators who are interested in cultural activities have been cordially invited as corporate community members to manage and proceed the prospective scheme on the basis of the tourism by community, which is, later on, known as The tourism-promoting club of Koo-Kaa-Sing subdistrict. Although the past outcomes of operation were not quite successful but it is not to such a great extent of a complete failure. As a matter of fact, tourism activities by community have encouraged the community to apply good and invaluable belongings in their community such as historical remains, cultures and customs to highlight the tourism, which, in turn, may possibly result in conservation trend, for instance, different groups of cultures have been set up, they include the following: Groups: Groups of culinary arts; folk literature groups; the local people feel satisfied, affectionate to and proud of their own cultures. However, these trends conform to the saying "The community people have managed their own lives and have simultaneously managed the community tourism". This is solely a way of enhancing the strength of community. In particular, the community people have been so much stronger that they are now not only capable of solving their own community problems but they will also be able to cope with their future problems. That is to say, they are prepared for being 
guided/directed and they are further cautious about either dramatic or minor change of the community.

As for, the tour guidelines for the Koo-Kaa-Sing community to follow in the tourism management, include the establishment of the tourism network, the development of the club management in terms of administration, For instance, enhancing the club's responsibilities, strengthening the community club and applying the ritual traditions as an implement for management and directly allowing the interested groups of local people who are directly/affected by profit gaining or losing a primary candidate to have a better chance to enter into the joint venture or becoming an investment partner/an entrepreneur. Thus, by all means of this strategy the members will be enabled to realize to such a greater degree of their ownership. The greater recognition of their competent services, the greater determination and dedication to their jobs assigned. What's more, the paradigmatic adjustment made by the local government organization aiming for providing the officials with knowledge and innovative ideas of tourism by community as well as full support in the propagation of tourism, more or less, to assure tourists of the worthwhile attractions available and the unforgettable experience they will gain. Besides, even the tourism club is required to adapt itself with respect to administrative adjustment. The proposed guidelines will enable the resources management to be in conformity to the eco-cultural based education that is more likely to entail the creation and repeated production to be continuously inherited until their work and production processes turn out to become the systematic ideas including the systems of value and morality which are able to exhibit through the management of Organization and the systematized management of activities concerning various aspects of ways of living in connection to the conditions and contexts of nature in the Ecological systems to entail/give rise to the stability and strength of tourism management ${ }^{[5]}$.

\section{CONCLUSION}

The activities having been accomplished are as follows: Having developed the tourism-promoting club to such a degree of considerable strength; having developed learning bases to be equipped with knowledge exhibition boards; Having renovated the custom of sprinkling water onto pagodas and the "Bang Fai" ancient folk ceremony; Having organized training courses and field trips to provide the villagers with knowledge and understanding of the tourism by community; Having developed folk wisdom goods and having provided tourists who are interested in cultures with cultural markets where they can come to travel continuously and as a result, powerful cooperation among the community people taking place leading to cultural tourism management run by really strong community.

The following implications are for relevant sectors to consider when affordable contribution can be offered:

- The government sectors should adapt their paradigms in working. First of all, to treat the Community Cultures with respect including beliefs, customs, conventional rites of community, specially the Beliefs and the reasons behind the villagers' worship of God, especially the God ghost/spirit dwelling in the ancient remains/historical sites

- Local people in the community and the government officials, especially the Local personnel in Administrative Organizations should realize and appreciate the true significance of local Organizations, to provide firm/strong support of tourism management until they are capable of strongly standing on their own feet

- The fine arts department, ministry of culture/ cultural affairs, should make a great leap to transfer all the obligations of looking after/taking care of and also maintaining the historical sites ancient remains/ruins, to The Local Administration Organization to take over all the tasks of developing and conserving the invaluable ancient remains and all the historical sites in the community at their wit's end for sustainability in parallel to the society existence

\section{ACKNOWLEDGEMENT}

The researchers express their sincere appreciation for all of support provided and the referees for their helpful comments.

\section{REFERENCES}

1. Mukda Wichittrara and YukTi, 2005. Community Cultures. Rhetoric and Politics of Ethnic. Faa Deow Kan, Bangkok, Thailand, ISBN: 974-937595-5, pp: 38.

2. Sata, W., V. Vinai, P. Bowjai and P. Rithdet, 2008. Environmental change of Lompao dam communities in Northeast Thailand. J. Soc. Sci., 4: 334-337.

http://www.scipub.org/fulltext/jss/jss44334337.pdf 
3. Natsubha ChatTip, 2005. Community's Ideas on Economy: Theoretical Suggestions in Various Malti Social. 2nd Edn., Bangkok, Saang San, Thailand, ISBN: 974-92776-9-4, pp: 1934.

4. Sarobon Sintu, 2003. Tourism by Community: Ideas and Experiences from the Northern Part of Thailand. The Office of Research Support Fund, Chang-Mai, Thailand, ISBN: 974-9206-38-2, pp: 60.
5. Pantasen, A., P. Piampongsan, T. Pantasen and S. Piamyad, 2007. The Knowledge Synthesis of Sufficiency Economy. Research Funds Office, ISBN: 974-9666-94-1, pp: 312. 